\title{
Heterozygosity following half-sib recurrent selection in popcorn using isoenzyme markers
}

\author{
Liz Kazmirczak Pereira \\ Department of Cellular Biology and Genetic \\ Universidade Estadual de Maringá \\ Av. Colombo, 5790, CEP 87020900 \\ Maringá, PR, Brazil \\ Tel: 554432614040 \\ Fax: 554432627336 \\ E-mail: pereira@bol.com.br

\section{Carlos Alberto Scapim*} \\ Department of Agronomy \\ Universidade Estadual de Maringá \\ Av. Colombo, 5790, CEP 87020900 \\ Maringá, PR, Brazil \\ Tel: 554432614552 \\ Fax: 554432627336 \\ E-mail: cascapim@uem.br
}

\section{Claudete Aparecida Mangolin}

Department of Cellular Biology and Genetic

Universidade Estadual de Maringá

Av. Colombo, 5790, CEP 87020900

Maringá, PR, Brazil

Tel: 554432614040

Fax: 554432627336

E-mail: camangolin@uem.br

\section{Maria de Fátima Pires da Silva Machado}

Department of Cellular Biology and Genetic

Universidade Estadual de Maringá

Av. Colombo, 5790, CEP 87020900

Maringá, PR, Brazil

Tel: 554432614040

Fax: 554432627336

E-mail:mfpsmachado@uem.br

\author{
Cleso Antônio Patto Pacheco \\ National Research Center for Maize and Sorghum \\ Caixa Postal 152, CEP 35701970 \\ Sete Lagoas, MG, Brazil \\ E-mail: cleso@cnpms.embrapa.br

\section{Freddy Mora} \\ Department of Agronomy \\ Universidade Estadual de Maringá \\ Av. Colombo, 5790, CEP 87020900 \\ Maringá, PR, Brazil \\ Tel: 554432614552 \\ Fax: 554432627336 \\ E-mail: fmora@universiabrasil.net
}

Financial support: National Counsel of Technological and Scientific Development (CNPq), Coordination for the Improvement of Higher Education Personnel (CAPES), and Fundação Araucária - Foundation of the State of Paraná, Brazil.

Keywords: allozymes frequency, genetic distance, selection cycles, Zea mays.

Abbreviations: MDH: malate dehydrogenase

PAGE: polyacrylamide gel electrophoresis

QTLs: quantitative trait loci

*Corresponding author 
Isozyme biochemical marker may be useful tool for genomic analysis of maize populations undergoing recurrent selection. Thus, isozymes markers was utilized for assess the changes in the genetic variability and distance in a Brazilian composite population of popcorn following four cycles of recurrent selection for yield. One hundred and ninety-six half-sib families were evaluated from each cycle and the ten highest-yielding families $(5.2 \%)$ were recombined to produce the next cycle. Isozyme analysis considered 80 seedlings per cycle. Simple linear regression equations were estimated among the allele frequencies in each locus in function of the selection cycles, the genetic distances among the cycles and the average heterozygosity per locus for each cycle. Regression analysis did not reveal any common trend for changes in allele frequencies presumably due to selection. The estimates of the number of polymorphic locus, of the mean of allele per locus and the mean heterozygosity did not reveal any reduction in variability. It was concluded that four selection cycles did not cause relevant changes in the variability or genetic distance among the selection cycles of CMS-43 popcorn population. Isozymes markers analysis showed that the number of recombined half-sib families in recurrent selection was suitable.

Several recent studies have confirmed that use of isozyme analysis as biochemical markers can be useful for genomic assessment in Zea mays L. breeding programs. Zlokolica and Milošević (2001) identified and located quantitative trait loci (QTLs) in the Yugoslav maize population, estimating relationship between enzymes marker loci and the loci for QTLs utilizing 15 enzymes controlled by about 30 loci. In hybridization works of Tsanev et al. (2002) and Tsanev et al. (2003) components of enzymes specific to compare Zea mays x Tripsacum dactyloides hybrids and their parents were used, suggesting isozymes may be employed as markers for the identification of maize chromosomes in the hybrids as well, and isozymes of malate dehydrogenase (MDH) are supposed as a possible biochemical marker to evaluate the introgression of genes. Maize inbreeds studies have evidenced how isozyme markers are valuable for satisfy the need of precise characterization of crop materials in any established system for effective protection of plant varieties (Mauria et al. 2000).

Corn breeders have frequently used recurrent selection methods based on half-sib families, complete half-sibs and $S_{1}$ or $S_{2}$ progenies (Flint-Garcia et al. 2003; Carena, 2005). Recurrent selection is a population improvement method that increases the frequency of favorable alleles while maintaining genetic variation. Alleles are fixed rapidly and deleterious, homozygous alleles are exposed and eliminated early in selection (Doerksen et al. 2003). Revilla et al. (1997) worked with isozyme analysis performed on synthetic maize populations undergoing recurrent selection of grain yield. Their conclusions based on isozyme data supported the deductions made from agronomic information, revealing that three cycles of selection neither caused relevant changes on variability nor on genetic distance among cycles of selection of synthetic populations.

Corn half-sib families undergoing recurrent selection may be assessed with the greatest accuracy and precision so that the estimates are reliable and also properly represent the population assessed so that the inferences are valid, because the same individuals do not figure in several repetitions. The exactness will be greater with higher numbers of families, and precision increases with the number of repetitions; however, human and financial resources

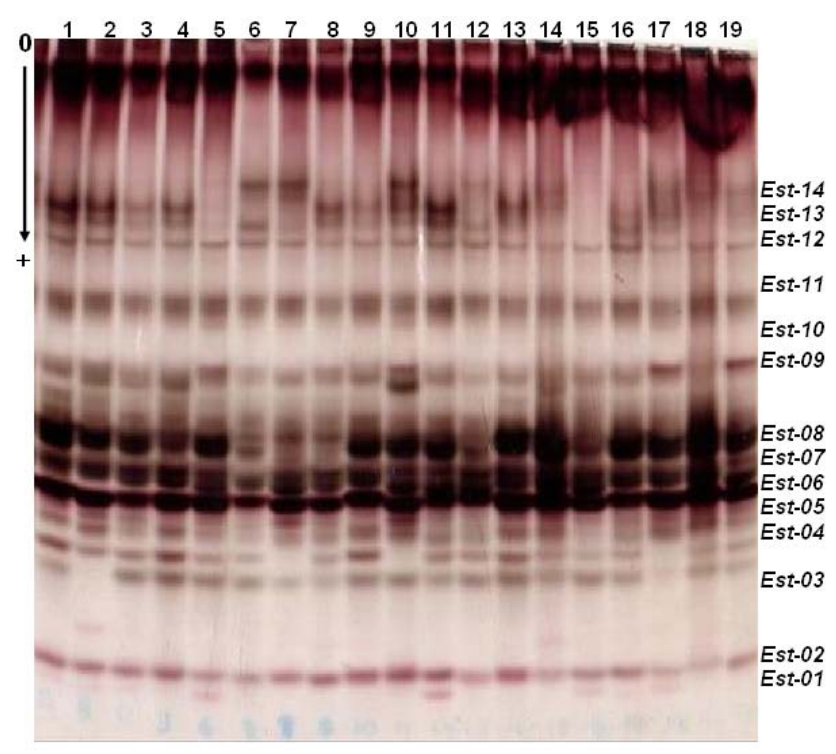

Figure 1. Esterase polymorphisms in native PAGE and Tris$\mathrm{HCl}, \mathrm{pH} 8.8$ for 19 individual coleoptiles (samples 1-19) obtained from $\mathrm{C} 2$ cycle of the popcorn composite CMS-43, showing $\alpha$ - and $\beta$-esterases produced from 14 loci. Two allele ( 1 = fast and $2=$ slow $)$ are observed in each one of the Est-1, Est2, Est-3, Est-4, Est-5, Est-6, Est-7, Est-8, Est-9, Est-13, Est-14 loci, and the Est-10, Est-11, and Est-12 loci are monomorphics. Polymorphisms observed at the 19 samples for each locus: Est-1 $1^{1 / 1}$ (samples 5, 11, 15-16), Est-1 ${ }^{2 / 2}$ (samples 1-4, 6-10, 12-14, 17-19), Est-2 ${ }^{1 / 1}$ (samples 1, 3-13, 15-19), Est-2 $2^{1 / 2}$ (samples 2, 14), Est-3 ${ }^{1 / 1}$ (samples 7, 10, 17), Est-3 $3^{2 / 2}$ (sample 2), Est-3 ${ }^{1 / 2}$ (samples 1, 3-6, 89, 11-16, 18-19), Est-4 ${ }^{1 / 1}$ (samples 4, 9, 12), Est-4 ${ }^{2 / 2}$ (sample 15), Est-4 ${ }^{1 / 2}$ (samples 1-3, 5-8, 10-11, 13-14, 16-19), Est-5 ${ }^{2 / 2}$ (samples 3, 6, 9, 11-12, 16, 19), Est-5 ${ }^{1 / 2}$ (samples 1-2, 4-5, 7-8, 10, 13-15, 17-18), Est-6 ${ }^{1 / 1}$ (samples 6, 16-17), Est-6 $6^{1 / 2}$ (samples 1-5, 7-15, 1819), Est-7 ${ }^{2 / 2}$ (samples 7-8), Est-7 $7^{1 / 2}$ (samples 1-6, 9-19), Est-8 $8^{1 / 1}$ (samples 3, 6-12, 19), Est-8 ${ }^{2 / 2}$ (sample 2), Est-8 ${ }^{1 / 2}$ (samples 1, 4, 5, 13-18), Est-9 $9^{1 / 1}$ (samples 6-9, 11-13, 15-16), Est-9 ${ }^{2 / 2}$ (samples 1, 5, 17-19), Est-9 ${ }^{1 / 2}$ (samples 2-4, 10, 14), Est-10, Est-11, Est-12 (samples 1-19; monomorphic), Est-13 ${ }^{1 / 1}$ (samples 6, 12), Est-13 ${ }^{1 / 2}$ (samples 1-5, 7-11, 13-19), Est-14 ${ }^{1 / 1}$ (samples 1-4, 11, 16, 18-19), Est-14 $^{2 / 2}$ (samples 5, 8, 9-10, 12), Est-14 ${ }^{1 / 2}$ (samples 6-7, 13-15, 17). 
Table 1. Allele frequencies of 19 loci for each selection cycle in the CMS-43 popcorn population and the estimates of the angular coefficient of the simple linear regression equation (b).

\begin{tabular}{|c|c|c|c|c|c|c|c|c|}
\hline \multirow{2}{*}{ Enzyme System } & \multirow{2}{*}{ Locus } & \multirow{2}{*}{ Allele } & \multicolumn{6}{|c|}{ CMS-43 } \\
\hline & & & $\mathrm{CO}$ & C1 & C2 & C3 & C4 & b \\
\hline \multirow{28}{*}{ Esterase } & \multirow{2}{*}{ Est-1 } & 1 & 0.23 & 0.25 & 0.20 & 0.22 & 0.17 & -0.015 \\
\hline & & 2 & 0.77 & 0.75 & 0.80 & 0.76 & 0.83 & 0.015 \\
\hline & \multirow{2}{*}{ Est-2 } & 1 & 0.84 & 0.80 & 0.60 & 0.60 & 0.21 & -0.146 \\
\hline & & 2 & 0.16 & 0.20 & 0.40 & 0.40 & 0.79 & 0.146 \\
\hline & \multirow{2}{*}{ Est-3 } & 1 & 0.53 & 0.45 & 0.44 & 0.35 & 0.44 & -0.028 \\
\hline & & 2 & 0.47 & 0.55 & 0.56 & 0.65 & 0.56 & 0.028 \\
\hline & \multirow{2}{*}{ Est-4 } & 1 & 0.58 & 0.53 & 0.53 & 0.69 & 0.59 & 0.018 \\
\hline & & 2 & 0.42 & 0.47 & 0.47 & 0.31 & 0.41 & -0.018 \\
\hline & \multirow{2}{*}{ Est-5 } & 1 & 0.36 & 0.42 & 0.38 & 0.38 & 0.41 & 0.006 \\
\hline & & 2 & 0.64 & 0.58 & 0.62 & 0.62 & 0.59 & -0.006 \\
\hline & \multirow{2}{*}{ Est-6 } & 1 & 0.48 & 0.68 & 0.88 & 0.75 & 0.28 & -0.033 \\
\hline & & 2 & 0.52 & 0.32 & 0.12 & 0.25 & 0.72 & 0.033 \\
\hline & \multirow{2}{*}{ Est-7 } & 1 & 0.56 & 0.49 & 0.91 & 0.91 & 0.37 & 0.004 \\
\hline & & 2 & 0.44 & 0.51 & 0.09 & 0.09 & 0.63 & -0.004 \\
\hline & \multirow{2}{*}{ Est-8 } & 1 & 0.61 & 0.61 & 0.53 & 0.51 & 0.75 & 0.018 \\
\hline & & 2 & 0.39 & 0.39 & 0.47 & 0.49 & 0.25 & -0.018 \\
\hline & \multirow{2}{*}{ Est-9 } & 1 & 0.24 & 0.39 & 0.53 & 0.51 & 0.38 & 0.040 \\
\hline & & 2 & 0.76 & 0.61 & 0.48 & 0.49 & 0.62 & -0.040 \\
\hline & \multirow{2}{*}{ Est-10 } & 1 & 1 & 1 & 1 & 1 & 1 & 0 \\
\hline & & 2 & 0 & 0 & 0 & 0 & 0 & 0 \\
\hline & \multirow{2}{*}{ Est-11 } & 1 & 1 & 1 & 1 & 1 & 1 & 0 \\
\hline & & 2 & 0 & 0 & 0 & 0 & 0 & 0 \\
\hline & \multirow{2}{*}{ Est-12 } & 1 & 1 & 1 & 1 & 1 & 1 & 0 \\
\hline & & 2 & 0 & 0 & 0 & 0 & 0 & 0 \\
\hline & \multirow{2}{*}{ Est-13 } & 1 & 0.47 & 0.65 & 0.62 & 0.56 & 0.27 & -0.05 \\
\hline & & 2 & 0.53 & 0.35 & 0.38 & 0.44 & 0.73 & 0.05 \\
\hline & \multirow{2}{*}{ Est-14 } & 1 & 0.63 & 0.62 & 0.66 & 0.49 & 0.70 & 0.00 \\
\hline & & 2 & 0.37 & 0.38 & 0.34 & 0.51 & 0.30 & 0.00 \\
\hline \multirow{10}{*}{$\begin{array}{c}\text { Malate } \\
\text { dehydrogenase }\end{array}$} & \multirow{2}{*}{$m M d h-1$} & 1 & 0.65 & 0.59 & 0.57 & 0.65 & 0.60 & 0.00 \\
\hline & & 2 & 0.35 & 0.41 & 0.43 & 0.35 & 0.40 & 0.00 \\
\hline & \multirow{2}{*}{$m M d h-2$} & 1 & 0.50 & 0.50 & 0.63 & 0.65 & 0.72 & $0.06^{*}$ \\
\hline & & 2 & 0.50 & 0.50 & 0.37 & 0.35 & 0.28 & $-0.06^{*}$ \\
\hline & \multirow{2}{*}{$m M d h-3$} & 1 & 1.00 & 1.00 & 1.00 & 1.00 & 1.00 & 0.00 \\
\hline & & 2 & 0.00 & 0.00 & 0.00 & 0.00 & 0.00 & 0.00 \\
\hline & \multirow{2}{*}{$s M d h-1$} & 1 & 1.00 & 1.00 & 1.00 & 1.00 & 1.00 & 0.00 \\
\hline & & 2 & 0.00 & 0.00 & 0.00 & 0.00 & 0.00 & 0.00 \\
\hline & \multirow{2}{*}{ sMdh-2 } & 1 & 1.00 & 1.00 & 1.00 & 1.00 & 1.00 & 0.00 \\
\hline & & 2 & 0.00 & 0.00 & 0.00 & 0.00 & 0.00 & 0.00 \\
\hline
\end{tabular}

necessary to carry out the studies also will be proportional to the number of families and repetitions present. The next and decisive step in genetic breeding is the correct number of families to be recombined to generate the next selection cycle.

It is well known in quantitative genetics that progress by selection is directly related to the selection differential. As the quantitative traits obey a normal distribution, a greater selection differential is obtained when a smaller proportion of superior units (individuals or families) is selected. Thus when progress is required in the short-term, a greater selection pressure can be used. However, under high selection pressure, a drastic reduction in the genetic variability is expected in the short-term, thus reducing the possibilities of selection in the medium and long-term
(Pinto et al. 2003; Hyrkas and Carena, 2005). Furthermore, higher selection pressures on small populations can result in problems related to the effective size of the population, increasing the possibility of the loss of important alleles due to genetic oscillation. There are few studies in the literature that define what would be suitable selection intensity. Habitually, for studies with family selection breeders, it has ranging from 10 to 25\% (Flachenecker et al. 2006).

The aim of this study was to assess the changes in the genetic variability and distance in a popcorn composite following four cycles of recurrent selection, recombination of 10 half-sib families in each cycle using esterase (EST; EC 3.2.1.) and (MDH; EC 1.1.1.37) isozymes as biochemical markers. Esterases in plants have been 
intensively explored as biochemical markers due its high allele polymorphism (Resende et al. 2000; Carvalho et al. 2003; Resende et al. 2004) and high number of loci using the polyacrilamide gel electrophoresis system (Pereira et al. 2001; Carvalho and Machado, 2004). MDH isozymes have been used to characterize and establish maize identity (Mauria et al. 2000) as a biochemical marker to evaluate introgression of genes (Tsanev et al. 2002), linkage groups in the chromosomes of hybrid species (Tsanev et al. 2003), for the analysis of variability behavior during selection cycles (Pinto et al. 2003), and most recently in popcorn $\mathrm{MDH}$ isozyme electrophoretic pattern has been well characterized (Pereira et al. 2006).

\section{MATERIALS AND METHODS}

The population of white grain "BRS-ÂNGELA" was improved for yield and popping expansion using six cycles of selection among and within half-sib progenies of the white popcorn composite CMS-43. This population, in turn, was selected based on the recombination of 33 white grain materials, selected from the Active Germplasm Bank because of their tolerance to Puccinia spp. and Helminthosporium turcicum, in 1979, at Embrapa National Research Center for Maize and Sorghum (CNPMS) (Pacheco et al. 1998). In all cycles 196 half-sib families were used and 10 families were selected based on the highest-yielding. This corresponded to $5.2 \%$ of the progenies assessed, indicating strong pressure on among progenies selection. These families were recombined and the next selection cycle started.
Five populations were used to study the genetic variability using enzymatic systems as biochemical markers, namely: CMS-43-C0-original cycle and the four subsequent cycles (C1, C2, C3 and C4). The complete description of two cycles can be found in Pacheco et al. (1998).

At least 200 seeds from each cycle were germinated on moist Germitest-type filter paper in a De Leo Germination Chamber with controlled moisture (distilled water) and temperature $\left(32^{\circ} \mathrm{C}\right)$, with a $12 \mathrm{hrs}$ light period for $72 \mathrm{hrs}$. Emergence and coleoptile development took place after this period.

Eighty seeds from each cycle were used for isozyme extraction to avoid problems because of the small sample size, and seedlings were chosen that presented coleoptiles approximately $15 \mathrm{~mm}$ long and $100 \mathrm{mg}$ mass. Synchronized seed germination is essential for analysis of material at the same stage of development, and $100 \mathrm{mg}$ of the sample was adequate to extract enough material for the esterase (EST; EC 3.1.1) and (MDH; EC 1.1.1.37) isozyme analysis.

After germination, coleoptiles obtained from each C0 - C4 cycles, measuring $15 \mathrm{~mm}$ length (approximately $100 \mathrm{mg}$ of tissue), were collected and individually homogenized with a glass rod in microcentrifuge tube using $20 \mu \mathrm{L}$ of $0.1 \mathrm{M}$ $\begin{array}{lllll}\text { Tris-HCl, } & \mathrm{pH} \quad 8.5, \quad \text { containing } 5 \% & \text { PVP-40 }\end{array}$ (polyvinilpyrrolidone-40), $11 \mathrm{mM}$ EDTA (ethylenediaminetetra acetic acid), 0.5\% Triton X-100, and $0.5 \% \beta$-mercaptoethanol solution. After homogenization,

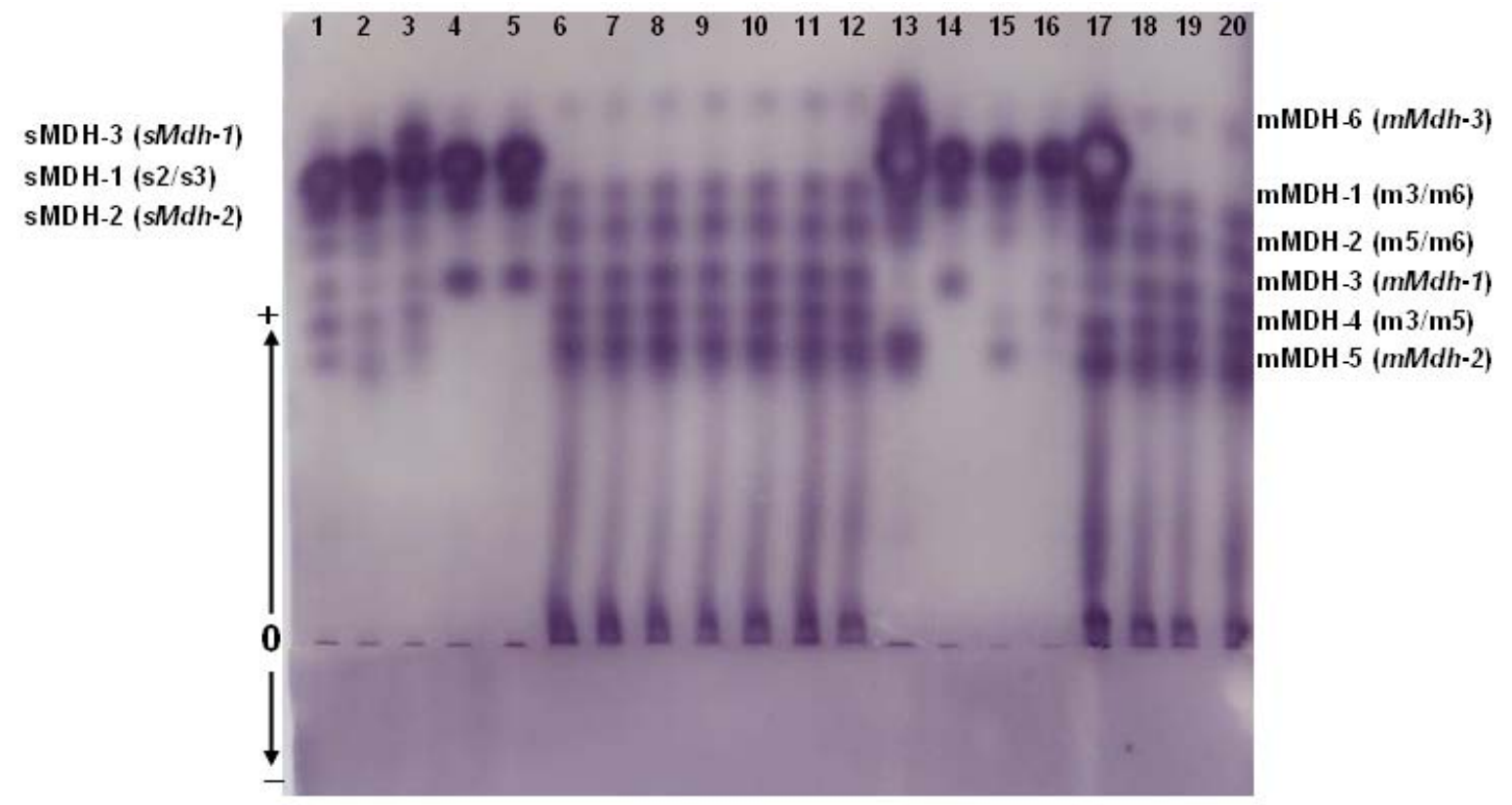

Figure 2. MDH isozymes pattern obtained in Histidine/Citric acid, pH 5.7, for coleoptile from $\mathrm{C2}$ cycle of the CMS-43 popcorn variety. Samples 1-5 and 13-17 show the cytosol (sMDH-1, sMDH-2, sMDH-3) and mitochondrial MDH (mMDH-1, mMDH-2, mMDH-3, $\mathrm{mMDH}-4, \mathrm{mMDH}-5, \mathrm{mMDH}-6$ ), and samples 6-12 and 18-20 show only the mMDH isozymes obtained by mitochondrial isolation procedures. 
the samples were centrifuged at $45.000 \mathrm{x}$ g for $30 \mathrm{~min}$ at $4^{\circ} \mathrm{C}$ in a Sigma $3 \mathrm{~K}-30$ centrifuge.

Native polyacrylamide gel electrophoresis (PAGE) was used to identify each $\alpha$ - and $\beta$-esterases. The polyacrylamide gels (14\%) were prepared using $0.375 \mathrm{M}$ Tris-HCl, pH 8.8, as buffer. Electrophoresis was performed for 5 hrs at $4^{\circ} \mathrm{C}$ using a constant voltage of $200 \mathrm{~V}$. The running buffer used was $0.1 \mathrm{M}$ Tris-glycine, $\mathrm{pH}$ 8.3. The gels were soaked for $30 \mathrm{~min}$ in $50 \mathrm{~mL} 0.1 \mathrm{M}$ sodium phosphate, $\mathrm{pH} 6.2$, at room temperature. Esterase activity was visualized by placing the gels for $1 \mathrm{hr}$ in a staining solution prepared with $50 \mathrm{~mL}$ of the sodium phosphate solution, $30 \mathrm{mg}$ of $\beta$-naphthyl acetate, $40 \mathrm{mg}$ of $\alpha$-naphthyl acetate, $60 \mathrm{mg}$ of Fast Blue RR salt, and $5 \mathrm{~mL}$ of $\mathrm{N}$ propanol.

Polyacrylamide gels were dried as described by Carvalho et al. (2003). The gels were kept at room temperature for $1 \mathrm{hr}$ in a mixture of $7.5 \%$ acetic acid and $10 \%$ glycerol embedded in $5 \%$ gelatin, placed between two sheets of wet cellophane paper stretched on an embroidering hoop and left to dry for 24-48 hrs.

Table 2. Mean heterozygosity $(\mathrm{H})$ in the different selection cycles of CMS-43 popcorn and their respective variances (V).

\begin{tabular}{|c|c|c|}
\hline Cycles & H & V \\
\hline 0 & 0.31260 & 0.04955 \\
\hline 1 & 0.32446 & 0.05175 \\
\hline 2 & 0.32201 & 0.05685 \\
\hline 3 & 0.30371 & 0.05055 \\
\hline 4 & 0.31040 & 0.05143 \\
\hline
\end{tabular}

$\mathrm{MDH}$ isozymes were analyzed by starch gel electrophoresis (14\% Penetrose-50 ${ }^{\circledR}$ ) prepared with 0.009 M L-histidine, $0.003 \mathrm{M}$ citric acid, $\mathrm{pH}$ 5.7, whereas the electrode buffer consisted of $0.065 \mathrm{M}$ L-histidine and $0.02 \mathrm{M}$ citric acid, $\mathrm{pH}$ 5.7. Electrophoresis was carried out at $10^{\circ} \mathrm{C}$, for $16-18 \mathrm{hrs}$, at $2.5 \mathrm{~V} \mathrm{~cm}^{-1}$ of gel. MDH isozymes were visualized with a staining solution containing $15 \mathrm{~mL} 0.1 \mathrm{M}$ Tris- $\mathrm{HCl}$ buffer, pH 8.6, 300 mg malic acid, 10 mg NAD ( $\beta$-nicotinamide dinucleotide), $1 \mathrm{mg}$ MTT (thiazolyl blue), $1 \mathrm{mg}$ PMS (phenazine methosulfate), and agar 2\% (Invitrogen). $\mathrm{MDH}$ isozymes were visualized after gel incubation for $30 \mathrm{~min}$ at $37^{\circ} \mathrm{C}$. For mitochondrial MDH analysis, mitochondria were isolated according to protocol by Day and Hanson (1978).

The $\alpha$ - and $\beta$-esterase and MDH isozyme electrophoretic patterns were used to calculate the genetic and genotypic frequencies. The null alleles were not considered and, therefore, some over-estimation of homozygous and underestimation of heterozygosity may have occurred if null alleles were present.
Simple linear regression analysis of each allele frequency on cycles of selection was carried out to determine if there were changes in the allele frequencies due to selection. Simple linear regression is known to over-estimate trends. However, if there are no common tendencies in the population and only weak trends were detected, we may assume that the isozyme variation cannot be explained by selection. According to Reif et al. (2005), the Nei genetic distance was used between the cycles and the heterozygosity mean per locus was estimated for each cycle.

The potential consequence of the founder effect in the allele frequencies was also quantified. The reduction in the number and frequency of some alleles would reduce the heterozygosity and, consequently, the genetic variability. However, other effects may be confounded with the founder effect. Reduction in heterozygosity would reflect deviation from the ideal condition due to the effects of the small size of the samples and non-random mating. The observed and expected heterozygotes were compared by $X^{2}$ tests (Revilla et al. 1997).

\section{RESULTS AND DISCUSSION}

The esterase isozyme pattern in coleoptiles from popcorn compost CM-43 recorded with $\alpha$-naphthyl acetate, $\beta$ naphthyl acetate showed $\alpha$ - and $\beta$-esterases produced from 14 loci. Esterase loci (Est-1 to Est-14) were numbered in sequence from the anode according to their decrease in negative charge (Figure 1). Different band esterases have characteristic colors, or rather, $\alpha$ (black), $\beta$ (red), and $\alpha \beta$ (a mixture of black and red), and they hydrolyze $\alpha$ - naphthyl acetate, $\beta$-naphthyl acetate, and $\alpha$ - and $\beta$-naphthyl acetate respectively (Figure 1). Two allele were observed in the Est-1, Est-2, Est-3, Est-4, Est-5, Est-6, Est-7, Est-8, Est-9, Est-13, and Est-14 loci, while the Est-10, Est-11, and Est12 loci were monomorphic within the CMS-43-C0-original cycle and the four subsequent cycles (C1, C2, C3 and C4) of popcorn populations (Table 1).

The mitochondrial MDH isozyme pattern, obtained by mitochondrial isolation procedure, reveals six mMDH isozymes produced from $m M d h-1, m M d h-2$, and $m M d h-3$ loci, and three sMDH were produced from two $s M d h-1$ and $s M d h-2$ loci (Figure 2). mMDH-1 and mMDH-2 isozymes are intergenic heterodimers between the $m M d h-1$ and $m M d h-3$ loci product and between the $m M d h-2$ and $m M d h-$ 3 loci product, respectively (Pereira et al. 2006); mMDH-3 and mMDH-5 isozymes correspond to homodimers produced by $m M d h-1$ and $m M d h-2$ loci, respectively, and mMDH-4 isozyme should be the intergenic heterodimer product of $m M d h-1$ and $m M d h-2$ loci. The mMDH- 6 isozyme is the homodimer produced by $m M d h-3$ locus. Figure 2 shows that mMHD-6 isozyme persists when 
soluble $\mathrm{MDH}$ isozymes are removed by mitochondrial isolation procedure. According to Pereira et al. (2006), the homodimer specified by standard $m M d h-3$ allele migrate to the sMDH-3 position and can be masked by homodimer soluble MDH enzyme. The sMDH-1/sMDH-2/sMDH-3 phenotype formed by three regularly spaced bands with the intermediate band being more intensely stained than the other bands seems to be a typical pattern to be expected for random binding of peptide chain produced by two genes (sMdh-1 and sMdh-2). Microbodies MDH isozymes $(\mathrm{mbMDH})$ are weakly stained in coleoptiles of CMS-43 popcorn (Figure 2) and fail to be not detected in all samples.

Thirteen of the 19 loci had more than one allele after four selection cycles among and within half-sib progenies in the CMS-43 popcorn population (Table 1). The proportion of polymorphic loci was $68 \%$ for all the cycles and thirty-six alleles were detected in the 19 loci (1.89 alleles per locus) (Table 1).

The variability detected in this population was less than the breeds of the Corn Belt Dent (Smith, 1986), Northern Flint or Southern Dent (Labate et al. 2003), but was greater than the variability reported for other populations (Reedy et al. 1995; Revilla and Tracy, 1995; Revilla et al. 1997). Reif et al. (2004) who investigated the molecular genetic diversity within and among maize populations affirm that genetic variability in maize is a valuable natural resource and plays a key role for future breeding progress and germplasm collections as a source of genetic diversity must be well characterized for efficient management and effective exploitation.

The first hypothesis to be considered is that the changes observed in the allele frequencies could be due to selection for yield. This was tested by the simple linear regression of the allele frequencies in function of the selection cycles. There was significant effect, $\mathrm{P} \leq 0.01$, only for the alleles of $m M d h-2$ locus. Revilla et al. (1997) have reported significant regression, precisely for alleles of the $M d h-2$ locus, of the allele frequency in function of the cycles ( $\mathrm{C} 0$, C1, C2 and C3) for the Spanish EPS6 corn population, using $S_{1}$ progenies. There was no tendency in the changes in the allele frequencies, presumably, due to selection for yield. Considering that simple linear regression overestimates the amount and significance of trends and that most trends were non-significant, we may conclude that the major proportion of the allozyme variation is not related to selection for yield.

Many authors have detected changes in the allele frequencies that are associated with selection for yield and other agronomic characteristics. Labate et al. (1999) examined the effects of breeding on allele frequency changes at molecular markers loci in two maize populations undergoing reciprocal recurrent selection, concluding that changes in heterozygosity due to inbreeding are confounded with changes resulting from selection and drift. Pollak et al. (1984) also detected correlations between allele frequencies of Acp-1 locus and yield, maturation and leaf variables, and the Got-1, Prx-1 (Peroxidase-1) and Adh-1 loci. Stuber et al. (1980) has reported correlations between the product of the loci Acp-1, Pgm-1, Glu-1, Mdh1 and yield. These two studies were related selection programs for yield and the only common locus among them was Acp-1, which did not significantly change in our study. Revilla et al. (1997) also not found associations between Acp-1 and yield. Labate et al. (1999) affirmed that grain yield also seems to be controlled by a large number of loci distributed throughout the genome, and the relationship between molecular marker data and grain yield indicates that grain yield may be a sensitive indicator of the heterozygosity level of a population.

For generations of random mating and more than 150 plants per generation, differences among the expected and observed heterozygote frequencies would reflect the following effects: natural selection, small sample size, scoring mistakes, mutation or migration (contamination). The $X^{2}$ tests for the differences between the observed and expected heterozygotes were not significant for the all tests performed (data not shown). Adjusting the significance levels for the multiple tests, with the standard Bonferroni technique of dividing the pre-determined significance level, $\alpha$, by the number of tests, the number of significant $X^{2}$ tests is severely reduced depending on the criteria used to fix the minimum number of expected heterozygotes.

A decrease was expected in the variability due to genetic drift because a recombination was carried out with only 10 superior progenies (5.2\%). There was no reduction in the variability over the successive cycles of selection. This observation was ratified by the results of the mean heterozygosity according to Table 2 .

No significant differences between pairs of mean heterozygosity were found. Thus, no reduction of

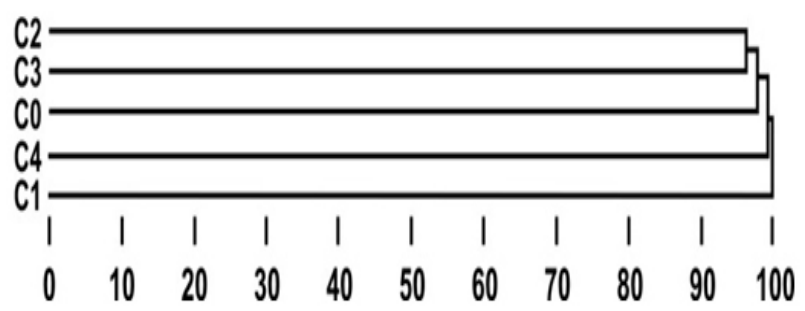

Figure 3. Dendrogram by the single linkage clustering method representing the genetic similarity among the selection cycles (C0, C1, C2, C3 and C4) constructed based on the Nei genetic distance matrix (Reif et al. 2005). 
heterozygosity was detected even thought only 10 superior progenies (5.2\%) were recombined in each cycle of selection. To reinforce this result, the agronomic data indicated that there was significant reduction in the genetic variability for yield after seven selection cycles (Pacheco et al. 1998). Thus the expected theoretical reduction in variability was not detected, when selection and recombination is made on a few individuals (Smith, 1986; Benson and Hallauer, 1994; Revilla et al. 1997). This conclusion was based on the isozyme data and confirms the lack of inbreeding depression revealed by the agronomic data (Pacheco et al. 1998) and is in line with several authors who have reported that inbreeding depression was not detected after several cycles of selection using selfed lines (Lamkey, 1992; Holthaus and Lamkey, 1995).

Genetic drift can effect of the frequency of rare alleles. In this study no modification was detected in the frequency of rare alleles. However, the assessment by Revilla et al. (1997) reported that the Mdh1-1, Prx1-5, Got2-2 and Got16 alleles showed alterations in frequency over the cycles.

It is important to verify whether the genetic distances based on isozyme markers are related to heterosis among the CMS-43 popcorn cycles. It would not be surprising if the correlation among the genetic distances and heterosis among the CMS-43 popcorn selection cycles was low and non-significant because the genetic distances correlated significantly with heterosis when the crosses among populations were genetically divergent. Selection for yield did not affect genetic distances among cycles of selection (Figure 3). The cycles are in diallel crosses in the 2004/2005 growing season.

No significant change in genetic variability and genetic distance (Figure 3) were detected for the half-sib progenies among the four selection cycles, indicating that in each cycle a suitable number of recombined families was adopted. It is not necessary to increase the number of recombined families, because it would imply reduction in the genetic gains and increased costs.

\section{CONCLUDING REMARKS}

Four selection cycles did not cause relevant changes in the variability or genetic distance among the selection cycles of CMS-43 popcorn population.

Isozymes markers analysis showed that the number of recombined half-sib families in recurrent selection was suitable.

\section{REFERENCES}

BENSON, Dirk L. and HALLAUER, Arnel R. Inbreeding depression rates in maize populations before and after recurrent selection. Journal of Heredity, March 1994, vol. 85, no. 2, p. $122-128$.

CARENA, Marcelo J. Maize commercial hybrids compared to improved population hybrids for grain yield and agronomic performance. Euphytica, January 2005, vol. 141, no. 3, p. 201-208.

CARVALHO, Vanda Marilza de; MARQUES, Rosimar Maria; LAPENTA, Ana Sílvia and MACHADO, Maria de Fátima P.S. Functional classification of esterases from leaves of Aspidosperma polyneuron M. Arg. (Apocynaceae). Genetics and Molecular Biology, March 2003, vol. 26, no. 2, p. 195-198.

CARVALHO, Vanda Marilza de and MACHADO, Maria de Fátima Pires da Silva. Esterase Polymorphism in remainder populations of Aspidosperma polyneuron M. Arg. (Apocynaceae). Revista Arvore, September-October 2004, vol. 28, no. 5, p. 625-631.

DAY, David A. and HANSON, John B. On methods for the isolation of mitochondria from etiolated corn shoots. Plant Science Letters, February 1978, vol. 11, no. 2, p. 99-104.

DOERKSEN, Trevor K.; KANNENBERG, Lyn W. and LEE, Elizabeth A. Effect of recurrent selection on combining ability in maize breeding populations. Crop Science, September-October 2003, vol. 43, no. 5, p. 16521658.

FLACHENECKER, Christian; FRISCH, Matthias; FALKE, K. Christin and MELCHINGER, Albrecht E. Trends in population parameters and best linear unbiased prediction of progeny performance in a European F2 maize population under modified recurrent full-sib selection. Theoretical and Applied Genetics, February 2006, vol. 112, no. 3, p. 483-491.

FLINT-GARCIA, Sherry A.; DARRAH, Larry L.; MCMULLEN, Michael D. and HIBBARD, Bruce E. Phenotypic versus marker-assisted selection for stalk strength and second-generation European corn borer resistance in maize. Theoretical and Applied Genetics, November 2003, vol. 107, no. 7, p. 1331-1336.

HOLTHAUS, Joel F. and LAMKEY, Kendall R. Population means and genetic variances in selected and unselected Iowa stiff stalk synthetic maize populations. Crop Science, November 1995, vol. 35, no. 6, p. 15811589.

HYRKAS, Alyson and CARENA, Marcelo J. Response to long-term selection in early maturing maize synthetic varieties. Euphytica, January 2005, vol. 143, no. 1-2, p. 4349. 
LABATE, Joanne A.; LAMKEY, Kendall R.; LEE, Michael and WOODMAN, Wendy L. Temporal changes in allele frequencies in two reciprocally selected maize populations. Theoretical and Applied Genetics, November 1999, vol. 99, no. 7-8, p. 1166-1178.

LABATE, Joanne A.; LAMKEY, Kendall R.; MITCHELL, Sharon E.; KRESOVICH, Stephen; SULLIVAN, Hillary and SMITH, John S.C. Molecular and historical aspects of corn belt dent diversity. Crop Science, January-February 2003, vol. 43, no. 1, p. 80-91.

LAMKEY, Kendall R. Fifty years of recurrent selection in the Iowa stiff stalk synthetic maize population. Maydica, January 1992, vol. 37, no. 1, p. 19-28.

MAURIA, S.; SINGH, N.N.; MUKHERJEE, A.K. and BHAT, K.V. Isozyme characterization of Indian maize inbreds. Euphytica, 2000, vol. 112, no. 3, p. 253-259.

PACHECO, Cleso A.P.; GAMA, Elto E.G.E.; GUIMARÃES, Paulo E. de Oliveira; SANTOS, Manoel X. dos and FERREIRA, Alexandre S.F. da Silva. Estimativas de parâmetros genéticos nas populações CMS-42 e CMS43 de milho pipoca. Pesquisa Agropecuária Brasileira, December 1998, vol. 33, no. 12, p. 1995-2001.

PEREIRA, Alvaro Júlio; LAPENTA, Ana Sílvia; VIDIGAL-FILHO, Pedro Soares and MACHADO, Maria de Fátima P.S. Differential esterase expression in leaves of Manihot esculenta Crantz infected with Xanthomonas axonopodis pv. manihotis. Biochemical Genetics, October 2001, vol. 39, no. 9-10, p. 289-296.

PEREIRA, Liz K.; MANGOLIN, Claudete A.; SCAPIM, Carlos A.; PACHECO, Cleso A.P.; BONATO, Carlos M. and MACHADO, Maria de Fátima P.S. Malate dehydrogenase isozyme patterns in four cycles of half-sib selection from CMS-43 popcorn variety (Zea mays L.). Maydica, January 2006, vol. 51, no. 3-4, p. 561-566.

PINTO, Luciana Rossini; VIEIRA, Maria Lucia Carneiro; SOUZA Jr., Cláudio Lopes de and SOUZA, Anete Pereira. Genetic-diversity assessed by microsatellites in tropical maize populations submitted to a high-intensity reciprocal recurrent selection. Euphytica, December 2003, vol. 134, no. 3, p. 277-286.

POLLAK, Linda M.; GARDNER, Charles O. and PARKHURST, Anne M. Relationships between enzyme marker loci and morphological traits in two mass-selected maize populations. Crop Science, January 1984, vol. 24, no. 6, p. 1174-1179.

REEDY, Mark E.; KNAPP, Allen D. and LAMKEY, Kendall R. Isozyme allelic frequency changes following maize (Zea mays L.) germplasm regeneration. Maydica, January 1995, vol. 40, no. 3, p. 269-273.

REIF, Jochen C.; XIA, Xuhua C.; MELCHINGER, Albrecht E.; WARBURTON, Marilyn L.; HOISINGTON, David A.; BECK, Dave; BOHN, Martin and FRISCH, Matthias. Genetic diversity determined within and among CIMMYT maize populations of tropical, subtropical, and temperate germplasm by SSR markers. Crop Science, January 2004, vol. 44, no. 1, p. 326-334.

REIF, Jochen C.; MELCHINGER, Albrecht E. and FRISCH, Matthias. Genetical and mathematical properties of similarity and dissimilarity coefficients applied in plant breeding and seed bank management. Crop Science, January-February 2005, vol. 45, no. 1, p. 1-7.

RESENDE, Adriana Gazoli; VIDIGAL-FILHO, Pedro Soares and MACHADO, Maria de Fátima P.S. Isozyme diversity in cassava cultivars (Manihot esculenta Crantz). Biochemical Genetics, August 2000, vol. 38, no. 7-8, p. 203-216.

RESENDE, Adriana Gazoli; VIDIGAL-FILHO, Pedro Soares and MACHADO, Maria de Fátima P.S. Esterase polymorphism marking cultivars of Manihot esculenta, Crantz. Brazilian Archives of Biology and Technology, July 2004, vol. 47, no. 3, p. 347-353.

REVILLA, Pedro and TRACY, William F. Isozyme variation and phylogenetic relationships among openpollinated sweet corn cultivars. Crop Science, January 1995, vol. 35, no. 1, p. 219-227.

REVILLA, Pedro; VALES, Maria I.; MALVAR, Rosa A. and ORDÁS, Amando. Allozyme frequencies, heterozygosity and genetic distances following $S_{1}$ recurrent selection in two synthetic maize populations. Theoretical and Applied Genetics, November 1997, vol. 95, no. 7, p. 1057-1061.

SMITH, J.S.C. Genetic diversity within the Corn Belt Dent racial complex of maize (Zea mays L.). Maydica, January 1986, vol. 31, no. 1, p. 349-367.

STUBER, C.W.; MOLL, R.H.; GOODMAN, M.M.; SCHAFFER, H.E. and WEIR, B.S. Allozyme frequency changes associated with selection for increased grain yield in maize (Zea mays L.). Genetics, May 1980, vol. 95, no. 1, p. 225-236.

TSANEV, V.; VLADOVA, R.; PETKOLICHEVA, K.; KRAPTCHEV, B. and MILANOV, C. Malate dehydrogenase, alcohol dehydrogenase, and 6phosphogluconate dehydrogenase isozymes of Zea mays L. $\mathrm{x}$ Tripsacum dactyloides L. hybrids and parents. Biologia Plantarum, December 2002, vol. 45, no. 4, p. 517-522. 
TSANEV, V.; VLADOVA, R.; PETKOLICHEVA, K.; KRAPTCHEV, B. and MILANOV, C. Glutamate oxaloacetic transaminase and malate dehydrogenase isozymes of Zea mays L. x Tripsacum dactyloides L. hybrids and parents. Biologia Plantarum, June 2003, vol. 47, no. 2, p. 189-194.

ZLOKOLICA, Marija and MILOŠEVIĆ, Mirjana. Isozymes as genetic markers in maize breeding. Biologia Plantarum, June 2001, vol. 44, no. 2, p. 207-211. 